\title{
Impact of coronavirus disease-2019 on chronic respiratory disease in South Korea: an NHIS COVID-19 database cohort study
}

Tak Kyu Oh and In-Ae Song*

\begin{abstract}
Background: The impact of underlying chronic respiratory diseases (CRDs) on the risk and mortality of patients with coronavirus disease 2019 (COVID-19) remains controversial. We aimed to investigate the effects of CRDs on the risk of COVID-19 and mortality among the population in South Korea.
\end{abstract}

Methods: The NHIS-COVID-19 database in South Korea was used for data extraction for this population-based cohort study. Chronic obstructive pulmonary disease (COPD), asthma, interstitial lung disease (ILD), lung cancer, lung disease due to external agents, obstructive sleep apnea (OSA), and tuberculosis of the lungs (TB) were considered CRDs. The primary endpoint was a diagnosis of COVID-19 between January 1st and June 4th, 2020; the secondary endpoint was hospital mortality of patients with COVID-19. Multivariable logistic regression modeling was used for statistical analysis.

Results: The final analysis included 122,040 individuals, 7669 (6.3\%) were confirmed as COVID-19 until 4 June 2020, and 251 patients with COVID-19 (3.2\%) passed away during hospitalization. Among total 122,040 individuals, 36,365 individuals were diagnosed with CRD between 2015 and 2019: COPD (4488, 3.6\%), asthma (33,858, 27.2\%), ILD (421, $0.3 \%)$, lung cancer $(769,0.6 \%)$, lung disease due to external agents (437, 0.4\%), OSA (550, 0.4\%), and TB (608, 0.5\%). Among the CRDs, patients either with ILD or OSA had 1.63-fold (odds ratio [OR] 1.63, 95\% confidence interval [CI] $1.17-2.26 ; P=0.004)$ and 1.65 -fold higher (OR 1.65, 95\% Cl 1.23-2.16; $P<0.001)$ incidence of COVID-19. In addition, among patients with COVID-19, the individuals with COPD and lung disease due to external agents had 1.56-fold (OR $1.56,95 \% \mathrm{Cl} 1.06-2.2 ; P=0.024)$ and 3.54-fold (OR 3.54, 95\% Cl 1.70-7.38; $P<0.001)$ higher risk of hospital mortality.

Conclusions: Patients with OSA and ILD might have an increased risk of COVID-19. In addition, COPD and chronic lung disease due to external agents might be associated with a higher risk of mortality among patients with COVID19. Our results suggest that prevention and management strategies should be carefully performed.

Keywords: Asthma, Chronic obstructive pulmonary disease, Interstitial lung diseases, Obstructive sleep apnea

\section{Background}

After the first report on 31 December 2019, 27 cases of coronavirus disease 2019 (COVID-19) with pneumonia of unknown etiology occurred in Wuhan city, Hubei,

\footnotetext{
${ }^{*}$ Correspondence: songoficu@outlook.kr

Department of Anesthesiology and Pain Medicine, Seoul National University Bundang Hospital, Gumi-ro 173 Beon-gil, Bundang-gu, Seongnam 13620, Korea
}

China [1]. The COVID-19 has been an outbreak worldwide, and the World Health Organization declared the Chinese outbreak of COVID-19 as a public health emergency of international concern on 30 January 2020 [2] and a pandemic crisis on 11 March 2020 [3]. As of 10 August 2020, approximately 5 million cases of COVID19, and 150,000 COVID-19 related deaths were reported in the United States [4]. To date, no vaccine is available 
for COVID-19 [5], and it is currently a public and global health crisis.

Previous studies have identified the important risk factors for worsening outcomes among patients with COVID-19, such as comorbidities, smoking, and obesity $[6,7]$. Among the comorbidities, chronic respiratory disease (CRDs) has the third-highest fatality ratio after cardiovascular disease and diabetes [8]. For example, chronic obstructive pulmonary disease (COPD) has been identified as a risk factor for severe status with high mortality in patients with COVID-19 [9]. However, asthma has not been identified as a risk factor for severe outcomes among patients with COVID-19 [10]. Thus, the impact of CRD on outcomes among patients with COVID-19 was reported in previous studies [11, 12]; however, the studies did not focus on the effect of CRD on the risks of COVID-19 among the general population and on patient outcomes. Thus, the relationship between underlying CRD and the risk of COVID-19 among the general population has not been identified. Furthermore, information regarding the risk of mortality in patients with COVID-19 with various CRDs is still lacking.

Therefore, we aimed to investigate various CRDs that affect the risk of COVID-19 among the general population in South Korea. Additionally, we examined the effect of different CRDs on hospital mortality among patients with COVID-19 in South Korea.

\section{Methods}

\section{Study design and ethical statement}

This population-based cohort study was conducted according to the Strengthening the Reporting of Observational Studies in Epidemiology guidelines [13]. The study protocol was approved by the institutional review board of Seoul National University Bundang Hospital (X-2004-604-905) and the Health Insurance Review and Assessment Service (NHIS-2020-1-291). Informed consent was waived because data analyses were performed retrospectively using anonymized data derived from the National Health Insurance Service (NHIS) in South Korea.

\section{NHIS-COVID-19 cohort database and study population}

The NHIS-COVID-19 cohort database was developed for medical research in cooperation between the NHIS and Korea Centers for Disease Control and Prevention (KCDC). The KCDC provides information on patients who were diagnosed with COVID-19 from 1 January 2020 to 4 June 2020, such as the confirmation date of COVID-19, the results of treatment, and the demographic information. However, NHIS and KCDC did not provide the data regarding patients with COVID19 who were undergoing treatment in the hospital as of
June 26th 2020, as their treatment results have not yet been determined. By using this information of patients with COVID-19, the NHIS extracted the control population using stratification methods with regard to age, sex, and residence in February 2020. In the NHIS-COVID-19 cohort database, all disease diagnoses by the International Classification of Diseases (ICD)-10 codes, and prescription information concerning drugs and/or procedures from 2015 to 2020 were included. An independent medical record technician at the NHIS center who was unaffiliated with this study performed data extraction on 26 June 2020. In this NHIS-COVID-19 cohort database, individuals who were $\geq 20$ years old were included in the study. In South Korea, patients who were diagnosed with COVID-19 were admitted to the hospital if they had severe symptoms such as pneumonia. However, if they had mild or no symptoms, they were isolated and closely monitored in certain government-managed centers. In addition, the KCDC tested all individuals for COVID-19 in South Korea, who had either direct or indirect contact with COVID-19 patients in the community or hospital.

\section{CRD}

The following diseases were considered as CRDs and the patient data extracted for this study included: COPD (J44*), asthma (J45*), interstitial lung disease (ILD, J84.9), lung cancer $\left(\mathrm{C} 34^{*}\right)$, lung disease due to external agent (J60-J70), obstructive sleep apnea (OSA) (G47.33), and tuberculosis of the lungs (TB, A15). The ICD-10 codes from 2015 to 2019 were used to evaluate CRDs in the study population. The study groups included the CRD group with individuals who were diagnosed with any type of CRD and the control group included the other individuals without any respiratory illnesses. In South Korea, as sole public insurance coverage, the CRDs should be registered in the NHIS database after diagnosis by physicians to receive financial coverage for treatment.

\section{Endpoints}

The primary endpoint of this study was the diagnosis of COVID-19, and it was evaluated from 1 January 2020 to 26 June 2020. The secondary endpoint of this study was hospital mortality among patients who were diagnosed with COVID-19.

\section{Data collection}

Additional data collected included (1) demographic information (age and sex), (2) place of residence (Seoul, Gyeonggi-do, Daegu, Gyeongsangbuk-do, and Other areas), (3) underlying disability, (4) income level in 2020, and (5) the Charlson comorbidity index (CCI), which was calculated based on registered ICD-10 diagnostic codes (Additional File 1) from 1 January 2019 to 31 December 
2019. The income level was divided into four groups using quartile ratio, and the patients were divided into seven age groups $(20-29,30-39,40-49,50-59,60-69$, $70-79$, and $\geq 80$ years). The annual income level of all individuals in South Korea is registered to determine yearly NHIS premiums. For this study, income levels were classified into quartile groups. In addition, in South Korea, the total disability of all individuals should be registered in the NHIS database to receive various benefits; it includes physical and brain lesion disabilities; visual disturbance; hearing and speech disabilities; autism; intellectual, mental, renal, heart, and respiratory disorders; hepatopathy; facial disfigurement; intestinal and urinary fistulae; and epilepsy.

\section{Statistical analysis}

The baseline characteristics of all individuals in this study were presented as percentages for categorical variables and mean values with standard deviations for continuous variables. Comparison of characteristics between the CRD and control groups was performed using the t-test for continuous variables and the chi-squared test for categorical variables. We constructed a multivariable logistic regression model to investigate whether CRD was associated with the progression of COVID-19 in South Korea, and it was defined as multivariable model 1. All covariates were included in the model for multivariable adjustment, however, the CCI was included in the other model to avoid multi-collinearity with other underlying diseases that were used for the CCI calculation. In addition, as a sensitivity analysis, we divided the CRD group into seven disease groups and included them in the multivariable logistic regression model for the analysis of the progression of COVID-19 in South Korea, and it was defined as multivariable model 2 . The CCI was included in the multivariable model 2 for adjustment, while other underlying diseases that were used for the CCI calculation were not included in the multivariable model 2 .

Further, we developed a multivariable logistic model for hospital mortality among patients who were diagnosed with COVID-19 to investigate whether underlying CRD affected hospital mortality, compared to the control group. The two multivariable models (model 1 and model 2) were also constructed to investigate the association of a CRD and seven disease type of CRD with hospital mortality, separately. Hosmer-Lemeshow statistics was used to confirm the goodness of fit of multivariable models as $P>0.05$, and it was confirmed that there was no multicollinearity in all multivariable models of the entire cohort with a variance inflation factor of $<2.0$. The results of the logistic regression models were presented as odds ratios (ORs) with 95\% confidence intervals (CIs). A receiver operator characteristic (ROC) analysis was performed to validate the use of logistic regression analysis for this study. R software (version 3.6.3; R Foundation for Statistical Computing, Vienna, Austria) was used for all analyses, and $P<0.05$ was considered statistically significant.

\section{Results \\ Study population}

The cohort constituted 129,120 individuals, 4790 of whom were excluded (aged $<20$ years). The final analysis included 122,040 individuals; 7669 (6.3\%) were confirmed as COVID-19 cases until June 4th 2020. Among the 7669 patients with COVID-19, 251 (3.2\%) passed away during hospitalization (Fig. 1). The baseline characteristics of all individuals in the NHIS-COVID-19 cohort are presented in Table 1. There was no missing data in the NHIS-COVID-19 database, except for annual income level in 2121 individuals (1.7\%). However, they are not excluded in the analysis, and their income level was included as unknown to avoid bias from excluding them. A total of 36,365 individuals were diagnosed with CRD between 2015 and 2019: COPD (4488, 3.6\%), asthma (33,858, 27.2\%), ILD (421, 0.3\%), lung cancer $(769,0.6 \%)$, lung disease due to external agents (437, 0.4\%), OSA (550, $0.4 \%)$, and TB $(608,0.5 \%)$. The results of the comparison of characteristics between the CRD and control groups are presented in Table 2. The CCI in the CRD group was higher than control group (mean value: $2.7 \pm 3.3$ in CRD group vs $1.5 \pm 2.6$ in control group; $P<0.001$ ).

\section{Risk of COVID-19 in South Korea}

Table 3 shows the results of the multivariable logistic regression model for the progression of COVID-19 in South Korea. In multivariable model 1, the CRD group was not associated with the incidence of COVID-19 compared with the control group (OR 1.04, 95\% CI $0.99-1.09 ; P=0.156)$. However, in multivariable model 2 , the patients with ILD or OSA were associated with 1.63-fold (OR 1.63, 95\% CI 1.17-2.26; $P=0.004$ ) and 1.65-fold (OR 1.65, 95\% CI 1.23-2.16; $P<0.001$ ) higher incidence of COVID-19 than the control group. Patients with other $C R D$, such as asthma $(P=0.464)$, lung cancer $(P=0.533)$, lung disease due to external agents $(P=0.061)$, and TB $(P=0.372)$ were not associated with the incidence of COVID-19. Hosmer-Lemeshow statistics showed that the goodness of fit was appropriate in the models $(P>0.05)$, and the area under curve (AUC) of the multivariable models in ROC analyses was 0.81 (95\% CI 0.80-0.81).

\section{Hospital mortality among patients with COVID-19}

Table 4 shows the results of the multivariable logistic regression model for hospital mortality of COVID-19 patients. In multivariable model 1 , the CRD group was 


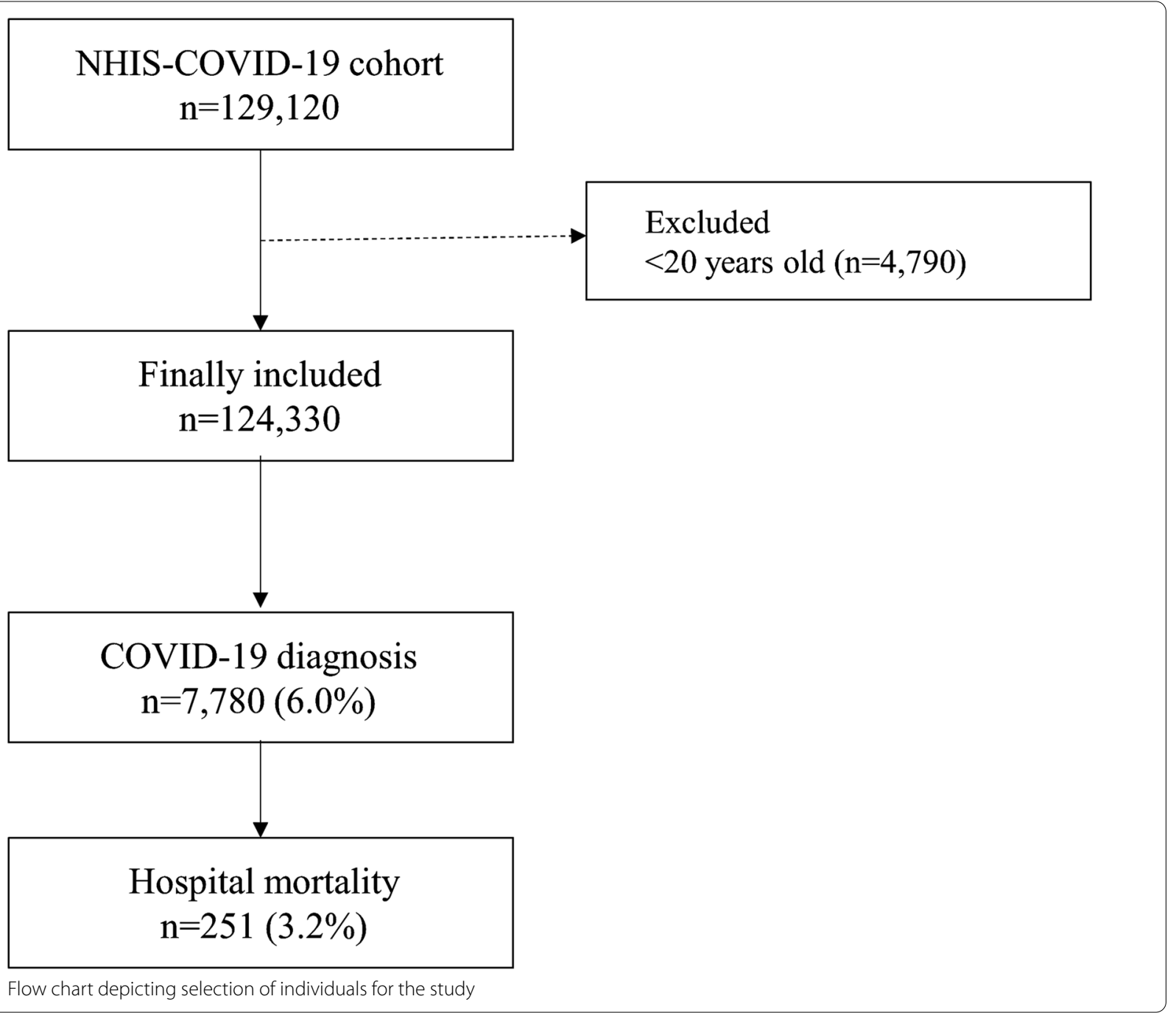

not associated with hospital mortality in COVID-19 patients compared with the control group (OR, 1.19; 95\% CI, 0.86-1.64; $P=0.299$ ). However, in multivariable model 2, the patients with COPD and lung disease due to external agents showed 1.56-fold (OR 1.56, 95\% CI 1.062.2; $P=0.024$ ) and 3.54-fold (OR 3.54, 95\% CI 1.70-7.38; $P<0.001)$ higher risk of hospital mortality of COVID19 patients compared with the control group. HosmerLemeshow statistics showed that the goodness of fit was appropriate in the models $(P>0.05)$, and the AUC of the multivariable models in ROC analyses was 0.83 (95\% CI 0.82-0.83).

\section{Discussion}

In the NHIS-COVID-19 database cohort, individuals with CRDs were not associated with both risk and hospital mortality for COVID-19 in South Korea. However, when the CRDs were divided into seven specific diseases, some CRDs were significantly associated either with a risk of infection or hospital mortality. Specifically, patients with ILD or OSA were associated with a higher incidence of COVID-19, while patients with COPD and lung disease due to an external agent were associated with increased hospital mortality.

OSA was a significant risk factor for COVID19 among the South Korean population, and this is an important factor in our study. Previous studies reported that obesity was an independent and significant risk factor for poor outcomes in patients with COVID-19 [14-18]. OSA might be one of the main factors that can be used to explain the impact of obesity/ OSA on COVID-19 [19]. Obesity is known to be highly correlated with the presence of OSA, and it was undiagnosed in the vast majority $[20,21]$. This is because OSA causes decreased lung function, and importantly, increased lung inflammation [22]. In addition, 
Table 1 Baseline characteristics of all individuals in NHISCOVID-19 cohort

\begin{tabular}{|c|c|c|}
\hline Variable & Number (\%) & Mean (SD) \\
\hline \multicolumn{3}{|l|}{ Age, year } \\
\hline $20-29$ & $32,380(26.0)$ & \\
\hline $30-39$ & $13,154(10.6)$ & \\
\hline $40-49$ & $16,519(13.3)$ & \\
\hline $50-59$ & $25,260(20.3)$ & \\
\hline $60-69$ & $19,669(15.8)$ & \\
\hline $70-79$ & $10,426(8.4)$ & \\
\hline$\geq 80$ & $6922(9.2)$ & \\
\hline Sex, male & $48,726(39.2)$ & \\
\hline \multicolumn{3}{|l|}{ Residence } \\
\hline Seoul & $8056(6.5)$ & \\
\hline Gyeonggi-do & $81,493(65.5)$ & \\
\hline Daegu & $6855(5.5)$ & \\
\hline Gyeongsangbuk-do & $15,107(12.2)$ & \\
\hline Other area & $12,819(10.3)$ & \\
\hline Underlying disability & $7655(6.2)$ & \\
\hline \multicolumn{3}{|l|}{ Income level } \\
\hline Q1 (Lowest) & $32,387(26.0)$ & \\
\hline Q2 & $24,979(20.1)$ & \\
\hline Q3 & $27,774(22.3)$ & \\
\hline Q4 (Highest) & $37,069(29.8)$ & \\
\hline Unknown & $2121(1.7)$ & \\
\hline Charlson comorbidity index & & $1.8(2.9)$ \\
\hline Hypertension & $32,727(26.3)$ & \\
\hline DM without chronic complication & $13,781(11.1)$ & \\
\hline DM with chronic complication & $4255(3.4)$ & \\
\hline Peripheral vascular disease & $7198(5.8)$ & \\
\hline Renal disease & $1392(1.1)$ & \\
\hline Rheumatic disease & $2958(2.4)$ & \\
\hline Dementia & $3926(3.2)$ & \\
\hline Peptic ulcer disease & $9872(7.9)$ & \\
\hline Hemiplegia or paraplegia & $568(0.5)$ & \\
\hline Moderate or severe liver disease & $146(0.1)$ & \\
\hline Mild liver disease & $13,612(10.9)$ & \\
\hline Cerebrovascular disease & $5763(4.6)$ & \\
\hline Congestive heart failure & $3683(3.0)$ & \\
\hline Myocardial infarction & $1187(1.0)$ & \\
\hline Malignancy & $22,013(17.7)$ & \\
\hline Metastatic solid tumor & $4072(3.3)$ & \\
\hline AIDS/HIV & $32(0.0)$ & \\
\hline Any chronic respiratory diseases & $36,365(29.2)$ & \\
\hline COPD & $4488(3.6)$ & \\
\hline Asthma & $33,858(27.2)$ & \\
\hline Interstitial lung disease & $421(0.3)$ & \\
\hline Lung cancer & $769(0.6)$ & \\
\hline Lung disease $\mathrm{d} / \mathrm{t}$ external agent & $437(0.4)$ & \\
\hline Obstructive sleep apnea & $550(0.4)$ & \\
\hline Tuberculosis of lung & $608(0.5)$ & \\
\hline
\end{tabular}

Table 1 (continued)

SD, standard deviation; DM, diabetes mellitus; AIDS, acquired immune

deficiency syndrome; HIV, Human Immunodeficiency Virus

angiotensin-converting enzyme (ACE) plasma activity is known to be increased in untreated patients with OSA [23]. Considering that the increase in ACE2 activity was related to organ injury and infectivity in patients with COVID-19 [24], OSA increases the risk of COVID-19 in patients included in this study via the ACE mechanism. However, our study did not show that OSA was associated with higher mortality of patients with COVID-19; therefore, more studies are needed in this regard.

Our study also reported that ILD patients had a higher risk of COVID-19. Although the exact mechanism is unknown, patients with ILD are known to be more susceptible to viral infection [25] because a respiratory viral infection causes an inflammatory reaction in the lung tissues. With these supporting pieces of evidence, the relationship between viral infection and ILD development is known to be closely linked [26]. Furthermore, patients with ILD often have dyspnea symptoms [27], making it difficult for them to wear masks. Since wearing masks is the most protective method for the prevention of COVID-19 [28], the poor compliance of mask-wearing in patients with ILD might elevate the risk of COVID-19.

Furthermore, we showed that patients with COPD had a 1.56-fold higher risk of hospital mortality after diagnosis of COVID-19. A meta-analysis reported in May 2020 reported that COPD was associated with a higher risk of mortality among patients with COVID-19 [9]. Among the total hospitalized patients with COVID-19, approximately $75 \%$ experienced pneumonia and $15 \%$ experienced acute respiratory distress syndrome (ARDS) [29], further, COPD is an independent risk factor for higher mortality in patients with pneumonia [30] and ARDS [31]. Thus, COPD can worsen hospital mortality in patients with COVID-19 as reported in a previous study [9]. Furthermore, ACE2, which is known to play an important role in lung injury among patients with COVID-19, was significantly elevated in patients with COPD [32], and they might be at a higher risk of mortality than the control group.

Interestingly, patients with COVID-19 and lung disease due to external agents had the highest risk among CRDs, with an OR of 3.54 (95\% CI 1.70-7.38). Patients with COVID-19 and a lung disease due to an external agent might have suffered from pneumoconiosis or pneumonitis due to external agents such as, asbestos, silica, inorganic dust, or chemicals. Although there is a lack of information regarding pneumoconiosis or pneumonitis due to external agents and the prognosis of patients with 
Table 2 Comparison of of characteristics between CRD group and control group

\begin{tabular}{|c|c|c|c|}
\hline Variable & CRD $n=36,365$ & Control $n=87,965$ & $P$ value \\
\hline Age, year & & & $<0.001$ \\
\hline $20-29$ & $6932(19.1)$ & $25,448(28.9)$ & \\
\hline $30-39$ & $3451(9.5)$ & $9703(11.0)$ & \\
\hline $40-49$ & $4503(12.4)$ & $12,016(13.7)$ & \\
\hline $50-59$ & $6787(18.7)$ & $18,473(21.0)$ & \\
\hline $60-69$ & $6806(18.7)$ & $12,863(14.6)$ & \\
\hline $70-79$ & $4534(12.5)$ & $5892(6.7)$ & \\
\hline$\geq 80$ & $3352(9.2)$ & $3570(4.1)$ & \\
\hline Sex, male & $36,228(41.2)$ & $12,498(34.4)$ & $<0.001$ \\
\hline Residence & & & $<0.001$ \\
\hline Seoul & $2367(6.5)$ & $5689(6.5)$ & \\
\hline Gyeonggi-do & $23,442(64.5)$ & $58,051(66.0)$ & \\
\hline Daegu & $2088(5.7)$ & $4767(5.4)$ & \\
\hline Gyeongsangbuk-do & $4716(13.0)$ & 10,391 (11.8) & \\
\hline Other area & $3752(10.3)$ & $9067(10.3)$ & \\
\hline Underlying disability & $3109(8.5)$ & $4546(5.2)$ & $<0.001$ \\
\hline Income level & & & $<0.001$ \\
\hline Q1 (Lowest) & $9758(26.8)$ & $22,629(25.7)$ & \\
\hline Q2 & $6681(18.4)$ & $18,298(20.8)$ & \\
\hline Q3 & $7815(21.5)$ & $19,959(22.7)$ & \\
\hline Q4 (Highest) & $11,492(31.6)$ & $25,577(29.1)$ & \\
\hline Unknown & $619(1.7)$ & $1502(1.7)$ & \\
\hline Charlson comorbidity index & $2.7(3.3)$ & $1.5(2.6)$ & $<0.001$ \\
\hline Hypertension & $12,896(35.5)$ & $19,831(22.5)$ & $<0.001$ \\
\hline DM without chronic complication & $5676(15.6)$ & 8105 ( 9.2) & $<0.001$ \\
\hline DM with chronic complication & $1897(5.2)$ & $2358(2.7)$ & $<0.001$ \\
\hline Peripheral vascular disease & $3306(9.1)$ & $3892(4.4)$ & $<0.001$ \\
\hline Renal disease & $663(1.8)$ & 729 ( 0.8) & $<0.001$ \\
\hline Rheumatic disease & $1325(3.6)$ & $1633(1.9)$ & $<0.001$ \\
\hline Dementia & $1940(5.3)$ & $1986(2.3)$ & $<0.001$ \\
\hline Peptic ulcer disease & $4397(12.1)$ & $5475(6.2)$ & $<0.001$ \\
\hline Hemiplegia or paraplegia & $255(0.7)$ & $313(0.4)$ & $<0.001$ \\
\hline Moderate or severe liver disease & $58(0.2)$ & $88(0.1)$ & 0.007 \\
\hline Mild liver disease & $5546(15.3)$ & 8066 ( 9.2) & $<0.001$ \\
\hline Cerebrovascular disease & $2635(7.2)$ & 3128 ( 3.6$)$ & $<0.001$ \\
\hline Congestive heart failure & $1905(5.2)$ & $1778(2.0)$ & $<0.001$ \\
\hline Myocardial infarction & $554(1.5)$ & $633(0.7)$ & $<0.001$ \\
\hline Malignancy & $8859(24.4)$ & $13,154(15.0)$ & $<0.001$ \\
\hline Metastatic solid tumor & $1886(5.2)$ & $2186(2.5)$ & $<0.001$ \\
\hline AIDS/HIV & $12(0.0)$ & $20(0.0)$ & 0.405 \\
\hline
\end{tabular}

Presented as mean with standard deviation or number with percentage

CRD, chronic respiratory disease; SD, standard deviation; DM, diabetes mellitus; AIDS, acquired immune deficiency syndrome; HIV, Human Immunodeficiency Virus

COVID-19, however, it might be associated with a poor prognosis [33]. Therefore, we can consider that patients with COVID-19 and either pneumoconiosis or pneumonitis due to external agents might suffer from severe pneumonia and ARDS, resulting in higher mortality than the control group.
Our study has several limitations. First, some important variables, including body mass index (BMI), were not included in the analysis because the information was unavailable in the NHIS database. Since obesity is closely related to the development of OSA [34], the lack of information on BMI might affect the results of this study. 
Table 3 Multivariable logistic regression model for development of COVID-19 in South Korea

\begin{tabular}{|c|c|c|}
\hline Variable & $\begin{array}{l}\text { Multivariable model } \\
\text { OR }(95 \% \mathrm{Cl})\end{array}$ & $P$-value \\
\hline Chronic respiratory diseases group (model1) & $1.04(0.99,1.09)$ & 0.156 \\
\hline \multicolumn{3}{|c|}{ Chronic respiratory diseases: sensitivity analyses (model2) } \\
\hline COPD & $0.96(0.85,1.09)$ & 0.553 \\
\hline Asthma & $1.01(0.96,1.07)$ & 0.464 \\
\hline Interstitial lung disease & $1.63(1.17,2.26)$ & 0.004 \\
\hline Lung cancer & $0.91(0.67,1.23)$ & 0.533 \\
\hline Lung disease $\mathrm{d} / \mathrm{t}$ external agent & $1.35(0.99,1.85)$ & 0.061 \\
\hline Obstructive sleep apnea & $1.65(1.23,2.16)$ & $<0.001$ \\
\hline Tuberculosis of lung & $0.92(0.75,1.11)$ & 0.372 \\
\hline \multicolumn{3}{|l|}{ Age, year } \\
\hline $20-29$ & 1 & \\
\hline $30-39$ & $0.94(0.86,1.02)$ & 0.153 \\
\hline $40-49$ & $0.86(0.80,0.93)$ & $<0.001$ \\
\hline $50-59$ & $0.74(0.69,0.79)$ & $<0.001$ \\
\hline $60-69$ & $0.60(0.55,0.66)$ & $<0.001$ \\
\hline $70-79$ & $0.47(0.42,0.52)$ & $<0.001$ \\
\hline$\geq 80$ & $0.38(0.33,0.44)$ & $<0.001$ \\
\hline \multicolumn{3}{|l|}{ Income level } \\
\hline Q1 (Lowest) & 1 & \\
\hline Q2 & $0.80(0.75,0.86)$ & $<0.001$ \\
\hline Q3 & $0.78(0.73,0.83)$ & $<0.001$ \\
\hline Q4 (Highest) & $0.83(0.78,0.88)$ & $<0.001$ \\
\hline Unknown & $0.75(0.62,0.91)$ & 0.004 \\
\hline Sex, male & $1.01(0.96,1.06)$ & 0.678 \\
\hline \multicolumn{3}{|l|}{ Residence } \\
\hline Seoul & 1 & \\
\hline Gyeonggi-do & $0.90(0.82,0.99)$ & 0.038 \\
\hline Daegu & $0.96(0.84,1.10)$ & 0.562 \\
\hline Gyeongsangbuk-do & $0.94(0.84,1.05)$ & 0.271 \\
\hline Other area & $0.89(0.79,1.00)$ & 0.053 \\
\hline Underlying disability & $1.11(1.00,1.22)$ & 0.041 \\
\hline Charlson comorbidity index (model 2) & $1.19(1.18,1.20)$ & $<0.0001$ \\
\hline Hypertension & $0.80(0.74,0.85)$ & $<0.001$ \\
\hline DM without chronic complication & $1.75(1.63,1.88)$ & $<0.001$ \\
\hline DM with chronic complication & $0.81(0.71,0.92)$ & 0.001 \\
\hline Peripheral vascular disease & $0.75(0.67,0.83)$ & $<0.001$ \\
\hline Renal disease & $0.91(0.75,1.11)$ & 0.371 \\
\hline Rheumatic disease & $0.98(0.85,1.12)$ & 0.734 \\
\hline Dementia & $1.96(1.72,2.22)$ & $<0.001$ \\
\hline Peptic ulcer disease & $1.48(1.37,1.59)$ & $<0.001$ \\
\hline Hemiplegia or paraplegia & $2.69(2.11,3.44)$ & $<0.001$ \\
\hline Moderate or severe liver disease & $0.59(0.33,1.06)$ & 0.076 \\
\hline Mild liver disease & $2.12(1.99,2.27)$ & $<0.001$ \\
\hline Cerebrovascular disease & $0.99(0.88,1.11)$ & 0.886 \\
\hline Congestive heart failure & $2.88(2.60,3.19)$ & $<0.001$ \\
\hline Myocardial infarction & $4.55(3.95,5.24)$ & $<0.001$ \\
\hline Malignancy & $2.04(1.93,2.15)$ & $<0.001$ \\
\hline Metastatic solid tumor & $0.95(0.84,1.07)$ & 0.387 \\
\hline AIDS/HIV & $4.21(1.84,9.64)$ & $<0.001$ \\
\hline
\end{tabular}


Table 3 (continued)

AUC of the multivariable models: 0.81 (95\% $\mathrm{Cl} 0.80$ to 0.81$)$

$\mathrm{OR}$, odds ratio; $\mathrm{Cl}$, confidence interval; COPD, chronic obstructive pulmonary disease; DM, diabetes mellitus; AIDS, acquired immune deficiency syndrome; HIV, Human Immunodeficiency Virus

Table 4 Multivariable logistic regression model for hospital mortality in COVID-19 patients $(n=7780$, death $=251,3.2 \%)$

\begin{tabular}{|c|c|c|}
\hline Variable & $\begin{array}{l}\text { Multivariable model } \\
\text { OR }(95 \% \mathrm{Cl})\end{array}$ & $P$-value \\
\hline Chronic respiratory diseases (model 1) & $1.19(0.86,1.64)$ & 0.299 \\
\hline \multicolumn{3}{|l|}{$\begin{array}{l}\text { Chronic respiratory diseases: sensitivity } \\
\text { analyses (model 2) }\end{array}$} \\
\hline COPD & $1.56(1.06,2.2)$ & 0.024 \\
\hline Asthma & $1.03(0.76,1.41)$ & 0.834 \\
\hline Interstitial lung disease & $1.83(0.74,4.55)$ & 0.193 \\
\hline Lung cancer & $1.82(0.80,4.14)$ & 0.154 \\
\hline Lung disease $\mathrm{d} / \mathrm{t}$ external agent & $3.54(1.70,7.38)$ & $<0.001$ \\
\hline Obstructive sleep apnea & $0.47(0.06,3.94)$ & 0.486 \\
\hline Tuberculosis of lung & $1.65(0.48,5.64)$ & 0.423 \\
\hline Age, 10 year increase & $2.85(2.40,3.38)$ & $<0.001$ \\
\hline \multicolumn{3}{|l|}{ Income level } \\
\hline Q1 (Lowest) & 1 & \\
\hline Q2 & $0.96(0.59,1.57)$ & 0.882 \\
\hline Q3 & $1.08(0.70,1.65)$ & 0.739 \\
\hline Q4 (Highest) & $0.89(0.652,1.30)$ & 0.554 \\
\hline Unknown & $0.67(0.18,2.54)$ & 0.560 \\
\hline Sex, male & $2.12(1.55,2.88)$ & $<0.001$ \\
\hline \multicolumn{3}{|l|}{ Residence } \\
\hline Seoul & 1 & \\
\hline Gyeonggi-do & $2.26(0.75,6.86)$ & 0.148 \\
\hline Daegu & $2.60(0.74,9.16)$ & 0.136 \\
\hline Gyeongsangbuk-do & $2.40(0.77,7.49)$ & 0.133 \\
\hline Other area & $1.69(0.50,5.72)$ & 0.401 \\
\hline Underlying disability & $1.33(0.94,1.89)$ & 0.109 \\
\hline Charlson comorbidity index, model 2 & $1.80(1.32,2.44)$ & $<0.001$ \\
\hline Hypertension & $1.36(0.89,2.06)$ & 0.153 \\
\hline DM without chronic complication & $1.87(1.35,2.59)$ & $<0.001$ \\
\hline DM with chronic complication & $1.61(1.06,2.45)$ & 0.027 \\
\hline Peripheral vascular disease & $1.19(0.81,1.76)$ & 0.76 \\
\hline Renal disease & $1.47(0.87,2.47)$ & 0.148 \\
\hline Rheumatic disease & $0.58(0.30,1.12)$ & 0.107 \\
\hline Dementia & $1.61(1.11,2.32)$ & 0.011 \\
\hline Peptic ulcer disease & $1.04(0.73,1.49)$ & 0.818 \\
\hline Hemiplegia or paraplegia & $1.92(1.03,3.59)$ & 0.040 \\
\hline Moderate or severe liver disease & $5.12(1.32,19.90)$ & 0.018 \\
\hline Mild liver disease & $0.80(0.58,1.10)$ & 0.170 \\
\hline Cerebrovascular disease & $0.57(0.38,0.87)$ & 0.009 \\
\hline Congestive heart failure & $1.91(1.38,2.66)$ & $<0.001$ \\
\hline Myocardial infarction & $0.79(0.47,1.33)$ & 0.374 \\
\hline Malignancy & $1.07(0.78,1.46)$ & 0.694 \\
\hline Metastatic solid tumor & $1.37(0.85,2.19)$ & 0.192 \\
\hline AIDS/HIV & $1.43(0.11,19.37)$ & 0.788 \\
\hline
\end{tabular}

AUC of the multivariable models: 0.83 ( $95 \% \mathrm{Cl} 0.82$ to 0.83 )

$\mathrm{OR}$, odds ratio; $\mathrm{Cl}$, confidence interval; $\mathrm{COPD}$, chronic obstructive pulmonary disease; DM, diabetes mellitus; AIDS, acquired immune deficiency syndrome; HIV, Human Immunodeficiency Virus
Second, we did not consider the most important lifestyle factor for CRDs such as smoking history in this study because the NHIS database did not contain the corresponding information. Third, we defined the CRDs and other comorbidities using ICD-10 codes from the NHIS database. However, there is a possibility that some individuals were not diagnosed with comorbidities, including CRDs, because of differences in the accessibility to medical sources. Lastly, a selection bias is possible, as patients with CRD might visit an outpatient clinic or hospital. Therefore, the risk of COVID-19 infection in patients with CRD might differ from other individuals.

\section{Conclusions}

In conclusion, among CRDs, OSA and ILD might increase the risk of COVID-19. In addition, COPD and chronic lung disease due to external agents might be associated with a higher risk of mortality among patients with COVID-19. Our results suggest that prevention and management strategies should be carefully performed.

\section{Supplementary information}

The online version contains supplementary material available at https://doi. org/10.1186/s12890-020-01387-1.

Additional File 1. The ICD-10 codes used by comorbidity to compute the Charlson comorbidity index

\begin{abstract}
Abbreviations
ACE: Angiotensin converting enzyme; AUC: Area under curve; $\mathrm{Cl}$ : Confidence interval; COPD: Chronic obstructive pulmonary disease; COVID-19: Coronavirus disease 2019; CRD: Chronic respiratory disease; ICD-10: International classification of diseases-10 code; ILD: Interstitial lung disease; KCDC: Korea centers for disease control and prevention; NHIS: National health insurance service; OR: Odds ratio; OSA: Obstructive sleep apnea; ROC: Receiver-operator characteristic.
\end{abstract}

\section{Acknowledgements}

Not applicable.

\section{Authors' contributions}

TKO and IAS contributed to the study design, analyzed the data, and drafted the first manuscript. TKO and IAS contributed to the data acquisition and critically revised the manuscript. Both authors read and approved the final version of the manuscript.

\section{Funding}

This research did not receive any specific grant from funding agencies in the public, commercial, or not-for-profit sectors.

\section{Availability of data and materials}

The data that support the findings of this study areavailable from National Health Insurance System, but restrictions apply to the availability of these data, which were used under licence for the current study and so are not publicly available. Data are, however, available from the authors upon reasonable 
request and with permission from the National Health Insurance System (https ://nhiss.nhis.or.kr/bd/ab/bdaba000eng.do).

\section{Ethics approval and consent to participate}

This population-based observational study was conducted and reported according to the Reporting of Observational Studies in Epidemiology guidelines. The study protocol was approved by the Institutional Review Board of Seoul National University Bundang Hospital (X-2004-604-905) and the Health Insurance Review and Assessment Service (NHIS-2020-1-291). Informed consent was waived because the data analyses were performed retrospectively using anonymized data derived from the South Korean NHIS database.

\section{Consent for publication}

Not applicable.

\section{Competing interests}

The authors declare that they have no competing interests.

Received: 1 October 2020 Accepted: 20 December 2020

Published online: 06 January 2021

\section{References}

1. Lu H, Stratton CW, Tang YW. Outbreak of pneumonia of unknown etiology in Wuhan, China: the mystery and the miracle. J Med Virol. 2020;92(4):401-2.

2. Novel CPEREJZIxbxzzZIz: The epidemiological characteristics of an outbreak of 2019 novel coronavirus diseases (COVID-19) in China. 2020, 41(2):145.

3. Bedford J, Enria D, Giesecke J, Heymann DL, Ihekweazu C, Kobinger G, Lane HC, Memish Z, Oh M-D, Schuchat AJTL: COVID-19: towards controlling of a pandemic. 2020, 395(10229):1015-1018.

4. Moore JTJMM, Report MW: Disparities in incidence of COVID-19 among underrepresented racial/ethnic groups in counties identified as hotspots during June 5-18, 2020-22 States, February-June 2020. 2020, 69.

5. Moore JP, Klasse PJ. COVID-19 vaccines: "Warp Speed" needs mind melds, not warped minds. J Virol 2020, 94(17).

6. Cai H. Sex difference and smoking predisposition in patients with COVID19. Lancet Respir Med. 2020;8(4):e20.

7. Guan WJ, Ni ZY, Hu Y, Liang WH, Ou CQ, He JX, Liu L, Shan H, Lei CL, Hui DSC, et al. Clinical characteristics of coronavirus disease 2019 in China. N Engl J Med. 2020;382(18):1708-20.

8. Epidemiology Working Group for Ncip Epidemic Response CCfDC. Prevention: [The epidemiological characteristics of an outbreak of 2019 novel coronavirus diseases (COVID-19) in China]. Zhonghua Liu Xing Bing Xue Za Zhi. 2020;41(2):145-51.

9. Alqahtani JS, Oyelade T, Aldhahir AM, Alghamdi SM, Almehmadi M, Alqahtani AS, Quaderi S, Mandal S, Hurst JR. Prevalence, severity and mortality associated with COPD and smoking in patients with COVID-19: a rapid systematic review and meta-analysis. PLOS ONE. 2020;15(5):e0233147.

10. Dong X, Cao YY, Lu XX, Zhang JJ, Du H, Yan YQ, Akdis CA, Gao YD. Eleven faces of coronavirus disease 2019. Allergy. 2020;75(7):1699-709.

11. Halpin DMG, Faner R, Sibila O, Badia JR, Agusti A. Do chronic respiratory diseases or their treatment affect the risk of SARS-CoV-2 infection? Lancet Respir Med. 2020:8(5):436-8.

12. Killerby ME, Link-Gelles R, Haight SC, Schrodt CA, England L, Gomes DJ, Shamout M, Pettrone K, O'Laughlin K, Kimball A, et al. Characteristics associated with hospitalization among patients with COVID-19 - Metropolitan Atlanta, Georgia, March-April 2020. MMWR Morb Mortal Wkly Rep. 2020;69(25):790-4.

13. Von Elm E, Altman DG, Egger M, Pocock SJ, Gøtzsche PC, Vandenbroucke JPJAoim: The strengthening the reporting of observational studies in epidemiology (STROBE) statement: guidelines for reporting observational studies. 2007, 147(8):573-577.

14. Bello-Chavolla OY, Bahena-Lopez JP, Antonio-Villa NE, Vargas-Vazquez A, Gonzalez-Diaz A, Marquez-Salinas A, Fermin-Martinez CA, Naveja J, Aguilar-Salinas CA: Predicting mortality due to SARS-CoV-2: a mechanistic score relating obesity and diabetes to COVID-19 outcomes in Mexico. J Clin Endocrinol Metab 2020, 105(8).

15. Cummings MJ, Baldwin MR, Abrams D, Jacobson SD, Meyer BJ, Balough EM, Aaron JG, Claassen J, Rabbani LE, Hastie J, et al. Epidemiology, clinical course, and outcomes of critically ill adults with COVID-19 in New York City: a prospective cohort study. Lancet. 2020;395(10239):1763-70.

16. Pettit NN, MacKenzie EL, Ridgway J, Pursell K, Ash D, Patel B, Pho MT: Obesity is associated with increased risk for mortality among hospitalized patients with COVID-19. Obesity (Silver Spring) 2020.

17. Kang L, Ma S, Chen M, Yang J, Wang Y, Li R, Yao L, Bai H, Cai Z, Xiang Yang B, et al. Impact on mental health and perceptions of psychological care among medical and nursing staff in Wuhan during the 2019 novel coronavirus disease outbreak: a cross-sectional study. Brain Behav Immun. 2020;87:11-7.

18. Palaiodimos L, Kokkinidis DG, Li W, Karamanis D, Ognibene J, Arora S, Southern WN, Mantzoros CS. Severe obesity, increasing age and male sex are independently associated with worse in-hospital outcomes, and higher in-hospital mortality, in a cohort of patients with COVID-19 in the Bronx New York. Metabolism. 2020;108:154262.

19. Memtsoudis SG, Ivascu NS, Pryor KO, Goldstein PA. Obesity as a risk factor for poor outcome in COVID-19-induced lung injury: the potential role of undiagnosed obstructive sleep apnoea. Br J Anaesth. 2020;125(2):e262-3.

20. Chan MTV, Wang CY, Seet E, Tam S, Lai HY, Chew EFF, Wu WKK, Cheng BCP, Lam CKM, Short TG, et al. Association of unrecognized obstructive sleep apnea with postoperative cardiovascular events in patients undergoing major noncardiac surgery. JAMA. 2019;321(18):1788-98.

21. Tham KW, Lee PC, Lim CH. Weight management in obstructive sleep apnea: medical and surgical options. Sleep Med Clin. 2019;14(1):143-53.

22. Rouatbi S, Ghannouchi I, Kammoun R, Ben Saad H. The ventilatory and diffusion dysfunctions in obese patients with and without obstructive sleep apnea-hypopnea syndrome. J Obes. 2020;2020:8075482.

23. Barcelo A, Elorza MA, Barbe F, Santos C, Mayoralas LR, Agusti AG. Angiotensin converting enzyme in patients with sleep apnoea syndrome: plasma activity and gene polymorphisms. Eur Respir J. 2001;17(4):728-32.

24. Ni W, Yang X, Yang D, Bao J, Li R, Xiao Y, Hou C, Wang H, Liu J, Yang D, et al. Role of angiotensin-converting enzyme 2 (ACE2) in COVID-19. Crit Care. 2020;24(1):422.

25. Britto CJ, Brady V, Lee S, Dela Cruz CS. Respiratory viral infections in chronic lung diseases. Clin Chest Med. 2017;38(1):87-96.

26. Vassallo R. Viral-induced inflammation in interstitial lung diseases. Semin Respir Infect. 2003;18(1):55-60.

27. Collard HR, Pantilat SZ. Dyspnea in interstitial lung disease. Curr Opin Support Palliat Care. 2008;2(2):100-4.

28. Feng S, Shen C, Xia N, Song W, Fan M, Cowling BJ. Rational use of face masks in the COVID-19 pandemic. Lancet Respir Med. 2020;8(5):434-6.

29. Rodriguez-Morales AJ, Cardona-Ospina JA, Gutierrez-Ocampo E, VillamizarPena R, Holguin-Rivera Y, Escalera-Antezana JP, Alvarado-Arnez LE, BonillaAldana DK, Franco-Paredes C, Henao-Martinez AF, et al. Clinical, laboratory and imaging features of COVID-19: A systematic review and meta-analysis. Travel Med Infect Dis. 2020;34:101623.

30. Restrepo Ml, Mortensen EM, Pugh JA, Anzueto A. COPD is associated with increased mortality in patients with community-acquired pneumonia. Eur Respir J. 2006:28(2):346-51.

31. Li S, Zhao D, Cui J, Wang L, Ma X, Li Y. Prevalence, potential risk factors and mortality rates of acute respiratory distress syndrome in Chinese patients with sepsis. J Int Med Res. 2020;48(2):300060519895659.

32. Leung JM, Yang CX, Tam A, Shaipanich T, Hackett TL, Singhera GK, Dorscheid DR, Sin DD: ACE-2 expression in the small airway epithelia of smokers and COPD patients: implications for COVID-19. Eur Respir J 2020, 55(5).

33. Shen HN, Jerng JS, Yu CJ, Yang PC. Outcome of coal worker's pneumoconiosis with acute respiratory failure. Chest. 2004;125(3):1052-8.

34. Romero-Corral A, Caples SM, Lopez-Jimenez F, Somers VK. Interactions between obesity and obstructive sleep apnea: implications for treatment. Chest. 2010;137(3):711-9.

\section{Publisher's Note}

Springer Nature remains neutral with regard to jurisdictional claims in published maps and institutional affiliations. 